\title{
Pineapple Waste and Wastewater: Route for Biodiesel Production from Candida tropicalis (MF510172)
}

\author{
Amruta Kanakdande 1 \\ https://orcid.org/0000-0003-4704-509X \\ Divya Agrwal ${ }^{1}$ \\ Chandrahasya Khobragade ${ }^{1 *}$ \\ https://orcid.org/0000-0002-4269-0017 \\ ${ }^{1}$ Swami Ramanand Teerth Marathwada University, School of Life Sciences, Department of \\ Biotechnology, Nanded MS, INDIA
}

Received: 2018.09.19; Accepted: 2019.07.13.

*Correspondence: e-mail cnkhobragade@gmail.com; Tel.: +91-9890796404 (C.K.)

\section{HIGHLIGHTS}

- Candida tropicalis (MF510172) was isolated from wastewater.

- Pineapple waste peels and filtered municipal wastewater are ideal for lipid production.

- Palmitic acid methyl esters are formed formed after transesterification of lipids.

- Wastewater recycling is better option to minimize the cost of final biodiesel.

\begin{abstract}
The aim of the present study was to utilize waste resources for biodiesel production and to test its recyclability. The oleaginous yeast was isolated from local municipal wastewater outlet and on the basis of $18 \mathrm{~S} r$ RNA sequencing, isolate was identified as Candida tropicalis (MF510172). Optimum fermentation conditions for lipid yield was recorded to be at $180 \mathrm{rpm}$ agitation speed, $6 \%$ pineapple waste as a carbon source, 5 $\%$ inoculum size, $48 \mathrm{~h}$ inoculum age at $40^{\circ} \mathrm{C}$ temperature with $72 \mathrm{~h}$ incubation time. Candia was able to produce $13 \mathrm{ml}$. $\mathrm{L}^{-1}$ lipids using optimum conditions. Extracted lipids were transesterified to form fatty acid methyl esters (FAME) and further characterized by using GC-MS and FTIR spectroscopy. Palmitic acid methyl esters and other supplementary hydrocarbon compounds were identified using GC-MS. FTIR spectrum indicates the characteristics FAME peak at $1740 \mathrm{~cm}^{-1}$ with $\mathrm{C}=\mathrm{O}$ stretching band of methyl esters. The results clearly demonstrate the waste resources containing filtered wastewater and pineapple waste used in the study are effective to produce quality oil for biodiesel production.
\end{abstract}

Keywords: Yeast; Waste resources; Biodiesel; Pineapple waste. 


\section{INTRODUCTION}

Presently a more sustainable future for society needs to face challenges like global energy demand, insufficient reservoirs of fossil fuels, and increasing emissions of greenhouse gases (GHG). To mitigate the consequences of climate change, volatility of oil prices (in particular for the transport sector) and geopolitical instability in fossil-fuel supplier regions etc. researchers are attracted for biodiesel production by exploring efficient technologies [1]. One of the major challenging tasks for biofuel production is the use of highcost feedstock. To defeat the problem associated with the use of high-cost feedstock; an alternative is to explore ideal waste substrates for lipid production using oleaginous yeasts strains. Generally, 25 - $40 \%$ of solid waste was generated after processing of fruits and vegetables from industries [2]. In India, about 0.7 million tones of pineapples are produced annually, from which 0.23 tons of solid waste is generated. These wastes are either uneconomically utilized or disposing of directly in the environment finally leading to serious pollution problems. Chemically, pineapple core extract comprises the highest contents of sugars such as fructose; glucose and sucrose as compared to other parts of pineapple waste extract [3]. These sugars can be easily utilized by yeasts and therefore would be the perfect choice for lipid production. Oleaginous yeasts abides many advantages like rapid growth in a short span, light independency, and easy scalability. Yeasts have unique abilities to utilize a wide range of carbon sources for lipid production like agro-industrial residues, wastewater [4], lignocellulosic wastes and by-products generated from different industries like organic acids, molasses and glycerol. These wide carbon sources can also contribute in improving the economical balance of various other processes [5]. Several reports are available denoting the use of different oleaginous microorganisms for the growth and production of lipids [6]. Oleaginous yeasts are generally found, in genera of Candida, Cryptococcus, Rhodotorula, Rhizopus, Trichosporon, Lipomyces and Yarrowia [7]. Among them, one of the attractive alternative oleaginous yeast is Candida for biofuel production. Earlier findings suggested preferring Candida for higher lipid production because it contains C16 to C18 fatty acids which are suitable for biodiesel synthesis [8].

Another aspect capturing great interests using wastewater for biodiesel production, as municipal wastewater (filtered) contains organic, inorganic and various mineral components ammonia $\left(\mathrm{NH}_{3}\right)$, phosphate $\left(\mathrm{PO}_{4}\right)$ and other essential nutrients which are required to promote microalgal growth. In addition to this trace metals present in wastewater such as $\mathrm{Fe}$, $\mathrm{Cu}, \mathrm{Mn}$ and $\mathrm{Zn}$ are essential for photosynthesis. Manorajan Nayak reported that using domestic wastewater algal-bio-oil can be produced [9]. Zhou et al. reported that algae grown on wastewater was the most promising route for reducing the production costs associated with nutrients and water [10].

Considering these facts, present study emphasizes to utilize the municipal wastewater as a growth medium for the production of lipids. The recycling of wastewater for optimum lipid production using Candida was tested for optimization of the fermentation process in presence of pineapple waste as a carbon source.

\section{MATERIAL AND METHODS}

All the chemicals and organic solvents used for the experiment were analytical grades procured from HiMedia, Mumbai, India; Sigma Chemical Co., St. Louis, USA and Merck, Mumbai, India.

\section{Collection of Food wastes and waste water sample}

Waste food was collected from dumping sites of local Vishnupuri area, Nanded, and was used as oleaginous yeast isolation medium while wastewater sample (containing sewage, domestic, household, and industrial waste water common source outlet) were collected from main outlet source of Local Ramghat area, Nanded. Pineapple waste peels were collected 
from the local fruit market and were used as a sole source of carbon for the production of lipids.

Samples were collected in sterile glass containers and immediately transferred in the laboratory and stored into the refrigerator at $4^{\circ} \mathrm{C}$ temperature until further use.

\section{Isolation of oleaginous yeasts}

The collected waste food sample was grind finely and to this $50 \mathrm{mM} \mathrm{NaOH}$ was added in a ratio of $1: 2$, the mixture was incubated overnight at room temperature followed by centrifugation at $13000 \mathrm{~g}$ for $40 \mathrm{~min}$ at $13-15^{\circ} \mathrm{C}$ temperature [11]. After centrifugation, the sample was filtered through filter paper to obtain sludge. This sludge filtrate is utilized as a media component for isolation of yeast cells so as to reduce the cost of isolation medium.

Four types of media were designed to obtain potent diversified oleaginous yeast strains. First medium (M1) consists of about $100 \mathrm{ml}$ fined slurry-like food waste with $3 \%$ agar-agar and $0.05 \%$ ampicillin (500 mg. ml$\left.{ }^{-1}\right)$. Second medium (M2) includes centrifuged pellets (4 ml) of waste food samples diluted with $(100 \mathrm{ml})$ of deionized water by the addition of $3 \%$ agar and $0.05 \%$ ampicillin antibiotics. Third medium (M3) includes $100 \mathrm{ml}$ filtrated waste water with $3 \%$ agar agar and $0.05 \%$ ampicillin while fourth medium (M4) includes $100 \mathrm{ml}$ standard YPD isolation medium for yeasts using waste water sample source. Petri plates containing each medium were prepared separately to obtain oleaginous yeasts. Waste water sample (filtrated) were spread on to each isolation medium and plates were incubated for 3 - 4 days at a temperature of $37^{\circ} \mathrm{C}$ in the incubator so as to grow diversified oleaginous yeast cells. Early grown pure cultured yeast cells were subcultured and pure cultured colonies were stored on YPD slants in the refrigerator at $4{ }^{\circ} \mathrm{C}$ temperature.

\section{Screening and Production of potent yeast}

The primary screened eleven colonies were carried forward for Methylene blue and Sudan black B staining to test the viability of cells and lipid staining respectively $[12,13]$.The isolated colonies were streaked on Yeast Malt Agar medium (YMA) (1\% glucose, $0.5 \%$ peptone, $0.3 \%$ yeast extract, $0.3 \%$ malt extract, $1.5 \%$ agar, $\mathrm{pH} 6.8$ ) with Methylene blue as an indicator. Plates were incubated at $37^{\circ} \mathrm{C}$ temperature for $48 \mathrm{~h}$.

\section{Activation and production of lipids}

Selected early grown and screened strains (03) were subjected for lipid production. To check the production efficiency of selected yeast strains, four types of cost-effective media were designed as P1, P2, P3 and P4. Three screened yeast strains were activated for production purpose. The activation medium contains $2 \%$ glucose, $0.5 \%$ yeast extract, $0.5 \%$ peptone and $0.15 \% \mathrm{MgSO}_{4} .7 \mathrm{H}_{2} \mathrm{O}$ and the $\mathrm{pH}$ was adjusted to 6.0 . The flasks containing activation media were incubated and stored in a rotary shaker at $180 \mathrm{rpm}$ for $48 \mathrm{~h}$ at $37^{\circ} \mathrm{C}$ [14].

Production medium with $0.12 \%$ yeast extract was used as a standard nitrogen source in all media with varying carbon sources (std. glucose and pineapple waste) and water as a medium (distilled or municipal waste water filtrated). Production medium P1 includes $6 \%$ glucose in $100 \mathrm{ml}$ of distilled water as a standard medium; P2 includes $6 \%$ pineapple waste as a carbon source in $100 \mathrm{ml}$ distilled water. P3 contains $6 \%$ glucose in $100 \mathrm{ml}$ of filtered wastewater while P4 contains $6 \%$ pineapple waste in $100 \mathrm{ml}$ of filtered waste water.

Early grown three pre-screened yeast strains from each individual petri plates were picked up and loopful of culture were used to activate the culture broth. About $5 \%$ inoculum were inoculated in to the production medium (P1, P2, P3 and P4) separately and incubated for $96 \mathrm{~h}$ at $180 \mathrm{rpm}$ agitation speed as one set and $110 \mathrm{rpm}$ as another set separately at 40 ${ }^{\circ} \mathrm{C}$ temperature to determine the agitation effect on lipid production [15]. Distilled water or waste water obtained after the first centrifugation cycle were used for next two fermentation cycles to check the production yield of lipids at 110 and $180 \mathrm{rpm}$ with respective media. 


\section{Extraction of lipids}

A modified method of Bligh and Dyer were used for extraction of lipids. The media (P1 to $\mathrm{P} 4)$ were centrifuged at $13000 \mathrm{rpm}$ for $25 \mathrm{~min}$ at $13^{\circ} \mathrm{C}$ temperature. Centrifuged pellets were washed with $10 \mathrm{ml}$ of $2 \mathrm{M} \mathrm{HCl}$ solution in order to lyse the cells, followed by centrifugation at $10,000 \mathrm{rpm}$ for $13 \mathrm{~min}$ at $10^{\circ} \mathrm{C}$. The supernatant was removed, and the cell dry weight was recorded followed with the addition of methanol: chloroform: deionized water (10:5:4) and the flasks were kept in shaking incubator at $180 \mathrm{rpm}$ for about $2 \mathrm{~h}$. Instead of deionized water $1 \mathrm{M}, \mathrm{NaCl}$ solution was used with the same volume to prevent binding of acidic lipids to denatured lipids. For complete lipid extraction, chloroform: sodium sulphate (1.5\%): acetic acid $(0.5 \%)$ (5:5:2) were used. Addition of $0.5 \%$ acetic acid in water results in increased recovery of acidic phospholipids. The complete mixture was transferred to screw cap tubes and the lower layer of extracted lipids were measured quantitatively [16]. After complete evaporation of organic solvents oil yield were recorded.

\section{Recycling of waste water}

Fermentation cycles with respective media were performed to study the effective reuse of waste water obtained from the first centrifugation step. About $100 \mathrm{ml}$ of all fourfermentation media (P1 to P4) were inoculated with screened yeast activated culture (5\%) and incubated for $96 \mathrm{~h}$ with varying RPM. One set at $110 \mathrm{rpm}$ and another set at $180 \mathrm{rpm}$ are noted as first fermentation cycle. Loss of water in the first step of centrifugation in each production medium was recorded accordingly and to make a complete $100 \mathrm{ml}$ of production medium distilled water or waste water were added into it with the respective medium. An identical procedure was followed for all three consecutive cycles with four respective media and results were recorded in terms of lipid production.

\section{Qualitative test for Lipids}

Lipids were analyzed qualitatively by using thin layer chromatography (TLC). TLC plate was prepared using silica gel 60 slurry with chloroform: methanol (1:1). Plates were prepared and dried at $100^{\circ} \mathrm{C}$ for 30 min. The sample was spotted on to the plate with $1 \mathrm{~cm}$ distance from the bottom and the TLC was run by using chloroform: methanol: acetic acid: water (2.5: 1.5: $0.4: 0.2 \mathrm{vol} / \mathrm{vol}$.) as a mobile phase. After sufficient running $\left(2 / 3^{\text {rd }}\right)$ plate was kept in oven for air dry. The developed chromatogram was observed under lodine vapours for lipid analysis [17].

\section{Transesterification}

Extracted lipids were subjected to transesterification reaction so as to obtain Fatty acids Methyl esters (FAME), simply called biodiesel. Transesterification reaction was carried out using an acid catalyst (sulphuric acid $0.12 \%$ ) in $12 \mathrm{ml}$ of methanol. Methanol was mixed with strong sulphuric acid firstly and complete mixing was achieved by slight heating. After complete dissolution of acid in methanol, the solution was mixed with $1 \mathrm{ml}$ of extracted lipids (after rota evaporation). Reaction was carried for $90 \mathrm{~min}$. at $60-70^{\circ} \mathrm{C}$ in continuous stirring. After sufficient cooling, the $\mathrm{pH}$ of reaction mixture was adjusted to neutrality at $\mathrm{pH}$ 7.0. After washing with warm water the reaction mixture was added with an equal volume of ethyl acetate and allowed to stand for phase separation in a separating funnel. On the basis of gravitational force, fatty acid methyl ester ring was formed on top of the reaction mixture while glycerol and other impurities appeared at the bottom of separating funnel. Fatty acid methyl esters ring was analyzed using GCMS [18].

\section{Biodiesel characterization using GC-MS}


The fatty acid methyl ester (FAME) contents of biodiesel synthesized from Candida lipids were determined by using gas chromatography, model Shimadzu QP-2010 Plus with Thermal Desorption System TD 20 coupled with a mass spectrometer.

\section{Biodiesel characterization using FTIR}

Raw neutral lipids separated from TLC were firstly analyzed using FTIR spectrophotometer (TENSOR II, Brucker, Germany) equipped with an attenuated total reflectance (ATR), deuterated lanthanum alpha-alanine doped triglycine sulphate (DLaTGS) detector, mid infrared (MIR) source, potassium bromide (KBr), separator and single reflection horizontal platinum ATR accessory (Brucker, Germany) having a diamond ATR crystal. For spectral analysis, the crystal cell was washed with n-hexane, then biodiesel sample was placed on the crystal cell and the cell was clamped into the mount of the FTIR spectrometer. The spectra in the range of $4000-400 \mathrm{~cm}^{-1}$ were recorded and automatic signals gained were collected in 16 scans at a resolution of $4 \mathrm{~cm}^{-1}$ against a background spectrum recorded from the clean empty cell at a room temperature. The purity of FAME was checked by using FTIR spectrum.

\section{Statistical analysis}

All experiments were run in triplicate and a completely randomized design (CRD) was used. Data were subjected to analysis of variance (ANOVA). Comparison of means was carried out by Duncan's multiple range tests. The statistical analysis was performed using an SPSS package (SPSS 24.0 for Windows, SPSS Inc., Chicago, IL, USA).

\section{RESULTS}

\section{Isolation, Screening, and Identification of Oleaginous Yeast}

Total twenty-four oleaginous diversified yeast strains were isolated from wastewater using food waste samples with four different combinations of isolation media (M1-M4) depicted (Figure 1).

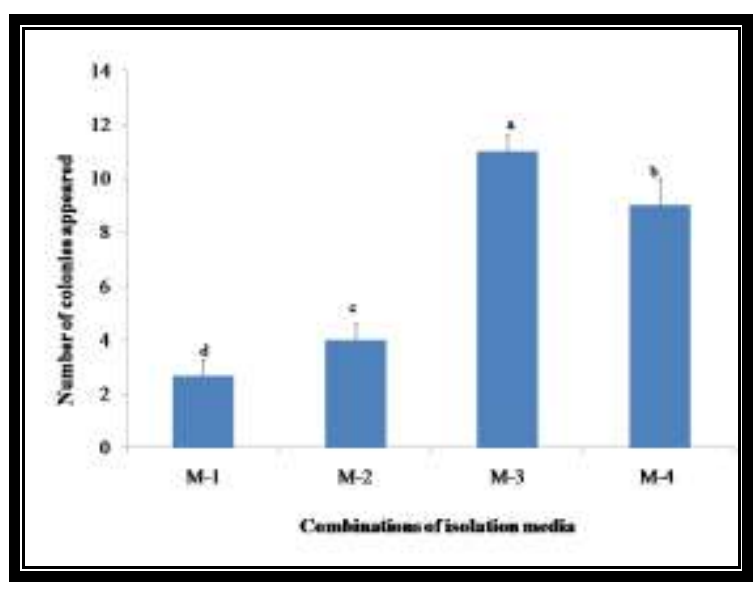

Figure1. Isolation media (M-1 to M-4) for potent lipid producer

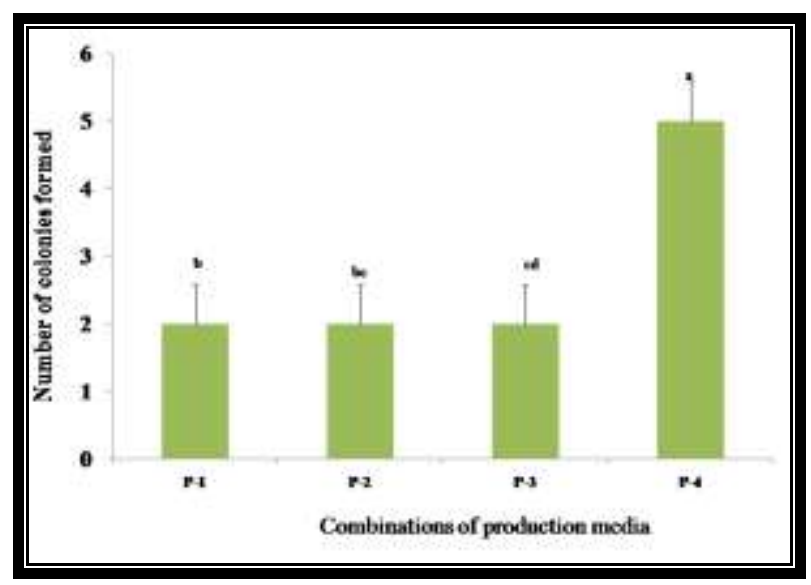

Figure2. Screened $M-3$ yeasts strains on different production media as $\mathrm{P}-1$ to $\mathrm{P}-4$

To minimize the overall cost of the biodiesel production process maximum waste resources were utilized. Maximum lipid producing yeast strains were reported in the medium M-3 (11). Different combinations of production media includes wastewater and distilled water as a medium $(100 \mathrm{ml})$ with $6 \%$ carbon sources like glucose and pineapple waste. Yeast extract $(0.12 \%)$ was used as a standard nitrogen source throughout the study. Production 
Medium P1 contains distilled water with glucose, P2 comprises distilled water with pineapple waste as a carbon source while P3 includes wastewater with glucose and P4 contains wastewater with pineapple waste (Figure 2).

Out of eleven screened isolates from M-3 medium only three potent, early grown oleaginous yeast strains revealed positive results towards Methylene blue and Sudan black B staining techniques. Methylene blue stain was used for checking the viability of cells, while Sudan black B stain was used for lipid staining. Depending upon yield of lipids in four medium (P1 to P4) from three efficient yeast strains, one potent yeast strain was able to produce the optimum lipids i.e. $13 \mathrm{ml} . \mathrm{L}^{-1}$ and selected this strain for further study.

The selected isolate was identified by using biochemical and $18 \mathrm{~S}$ rRNA sequencing technique and confirmed as Candida tropicalis. The phylogenetic tree was constructed with the MEGA 7.0 software to check the evolutionary relationship of isolated yeast strains with the available deposited 15 species of Candida. The isolated yeast strain nucleotide sequence was $99 \%$ similar with the Candida tropicalis. The nucleotide sequence was deposited to NCBI and received an accession number MF 510172 (Figure 3).

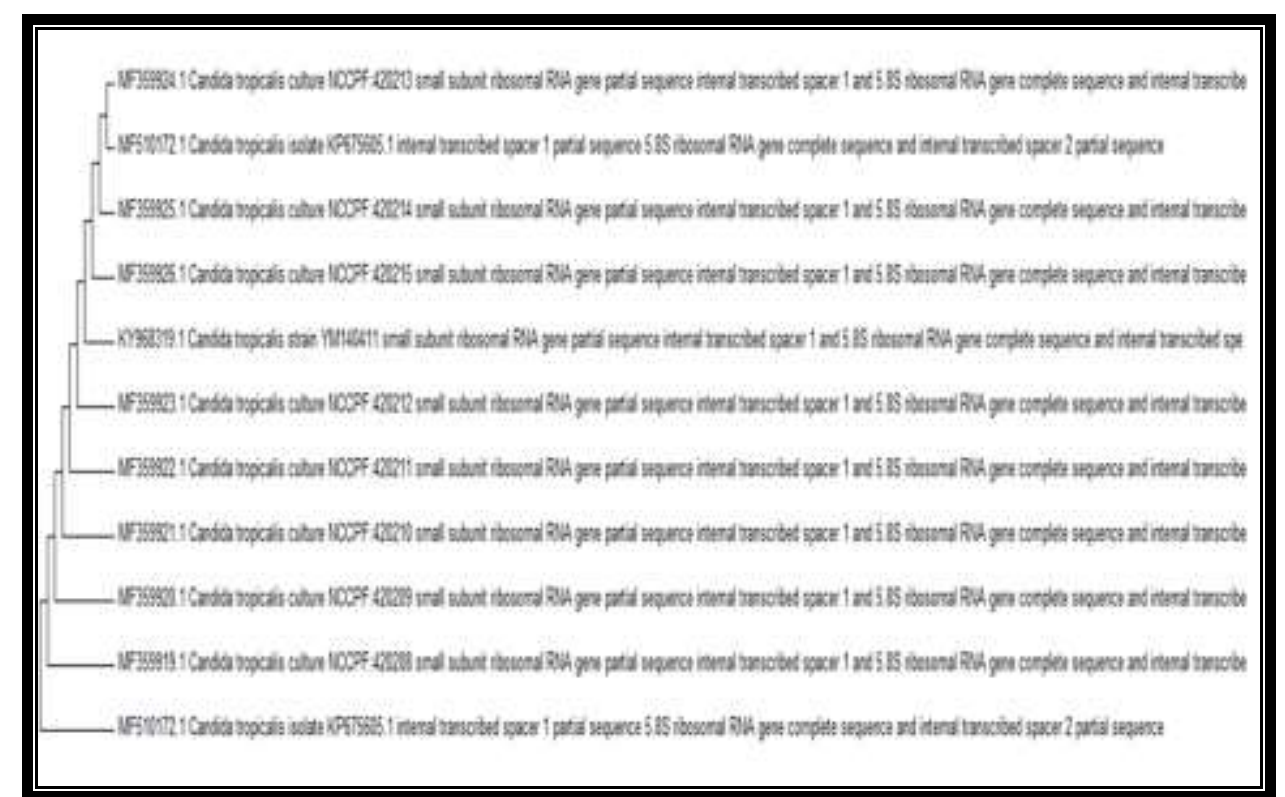

Figure 3. Phylogenetic tree of Candida tropicalis (MF510172) using MEGA 7.0 Software

The isolated Candida tropicalis revealed the accumulation of $58 \%$ lipids to its dry weight. In terms of bioprospecting, this unexplored yeast identified from the local wastewater sample needs to be exploited prior to improve genetically. The highest lipid yielding medium reported from the present investigation is wastewater containing pineapple waste as a carbon source (P4) however; substrate and type of organism also play an important role in lipid production. In terms of minimization of production cost of biofuel, use of wastewater as a growth medium and pineapple waste as a carbon source for Candida tropicalis yeast may prove to be a better option. The use of pineapple waste as sole source of carbon in production medium could eliminate the competition with agriculture in terms of space by adding value to the process. Thus, the designed principle prevents waste generation and ultimately contributes to an increasingly greener biotechnology [19].

\section{Production and Extraction of Lipids}

Total lipids were extracted ( $13 \mathrm{ml}$ volume) by using a modified method of Bligh and Dyer. After rota evaporation oil content was reported to be $13 \mathrm{ml} \cdot \mathrm{L}^{-1}$ of production medium. Generally, yeasts belonging to the genera of Candida, Cryptococcus, Lipomyces, Rhodotorula, Rhodosporidium, Trichosporon, and Yarrowia are found to be oleaginous in nature [20, 21].Commercial utilization of the lipid feedstock for biodiesel purpose depends upon the quantity of storage lipid and the quality of fatty acids present in the lipid producers 
[22]. Of the two tested carbon sources, pineapple waste revealed better results with the utilization of wastewater in replacement of distilled water (Figure 4) with different combinations of media.

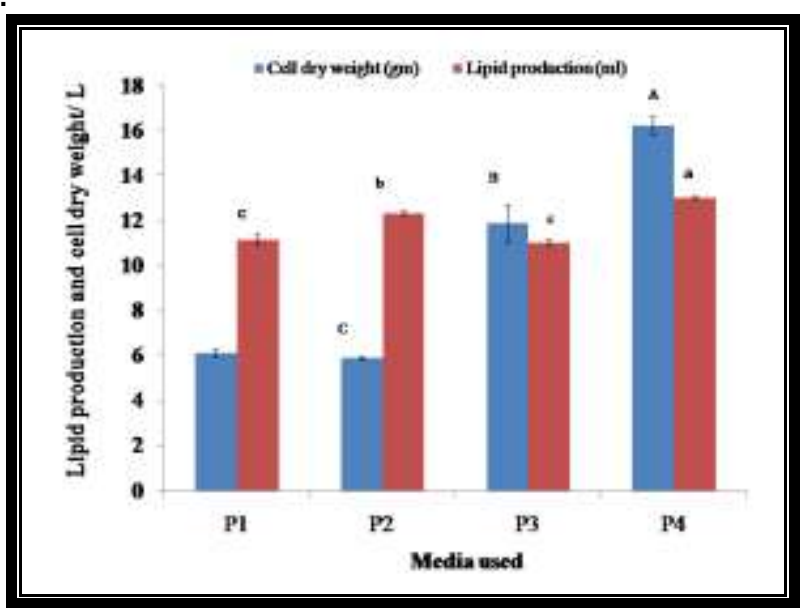

Figure 4. Effect of medium combinations on lipid production in $\mathrm{ml}$ and cell dry weight in $\mathrm{gm}$

Glucose as a standard carbon source yields $11.4 \mathrm{ml}^{-\mathrm{L}^{-1}}(\mathrm{v} / \mathrm{v})$ lipids using distilled water and glucose while same glucose yields $12.4 \mathrm{ml}^{-\mathrm{L}^{-1}}$ with the utilization of wastewater which clearly indicates the fact that wastewater yields more lipids than standard distilled water. Wastewater and pineapple waste utilization may be one of the future alternative process to minimize the issues related to waste management and environmental pollution. Wastewater used in the study showed the glucose concentration $1.2 \mathrm{mg} \cdot \mathrm{ml}^{-1}$, lipids $0.9 \mathrm{mg} \cdot \mathrm{ml}^{-1}$ at $\mathrm{pH}$ 7.78. It has been reported that different physicochemical factors affect the yield of lipids such as $\mathrm{pH}$ of the medium, temperature, agitation speed, aeration rate, carbon source, nitrogen source, and $\mathrm{C}: \mathrm{N}$ ratio of the medium.Agitation can cause shear forces, which influence the microorganism's morphology, variation in growth and metabolites formation [23]. Similar type of findings was reported with the dairy wastewater using $R$. opacus oleaginous strain by Nikhil Gupta for its applications as a biofuel [24].

\section{Effect of Aeration on Lipid Production and Cell Dry Mass}

An increase in agitation rate resulted in increased yield of lipids. This fact can be attributed to improved homogeneity of the culture medium and enhancement of heat and nutrient transfer in the culture medium which results in increase in microbial growth rate and metabolism-mediated product formation rate.

Agitation speed at 110 and $180 \mathrm{rpm}$ significantly affected the lipid production and cell dry weight using Candida tropicalis (MF510172). Results obtained from the study (Figure 5) at $180 \mathrm{rpm}$ agitation speed, lipid production in the first cycle was reported to be $12.8 \mathrm{ml}^{-1}$ while at $110 \mathrm{rpm}$ results in $7 \mathrm{ml} . \mathrm{L}^{-1}$ of lipids, which indicates agitation speed significantly affected the lipid production. Lipid yield was reported to be near about two times greater at $180 \mathrm{rpm}$ than $110 \mathrm{rpm}$ agitation speed in the first cycle. Similar types of results were obtained in second and third cycle of agitation. 


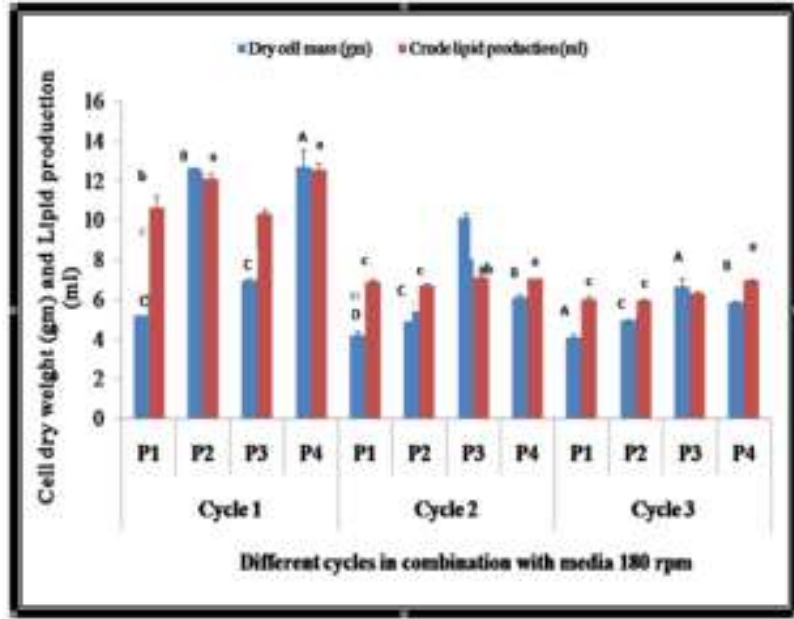

Figure 5. Lipid production with recycling of waste wastewater at $180 \mathrm{rpm}$ agitation speed

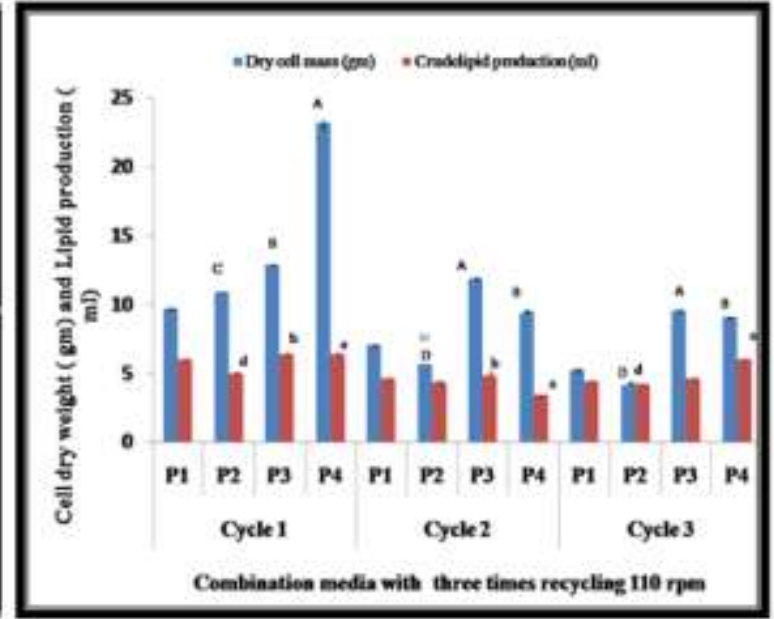

Figure 6. Lipid production with recycling of water with $110 \mathrm{rpm}$ agitation speed.

The agitation speed mainly causes the proper mixing of media components and shears in the fermentation process, thereby by making oxygen, heat, and a nutrient transfer efficiently in the fermentation broth and disperses the air into small bubbles to improve gasliquid contact area.This could prevent mycelial clustering and thus results in favour of oxygen absorption [25].

The results obtained from the study (Figure 6) at $110 \mathrm{rpm}$ agitation speed for $96 \mathrm{~h}$ incubation with $40^{\circ} \mathrm{C}$ temperature lipid yield was reported to be optimum in the first cycle i.e. $7 \mathrm{ml} . \mathrm{L}^{-1}$ followed by $6.4 \mathrm{ml}$ in second and $6.0 \mathrm{ml}$ in third fermentation cycle. At low agitation speed, the viscosity of fermentation broth generally increases and leads to a reduction in mass transfer efficiency causing less utilization of media components by the microorganisms thereby resulting in less yield of lipids [26].

It is imperative to recycle wastes including spent cell mass, mineral nutrients, different fruit wastes and wastewater generated from various sources to reduce wastes and the production costs of biofuel. Elsewhere it is reported that olive oil mill wastewater was utilized for the production of high value added lipids using the selected strains of Zygomycetes [27]. Using Aspergillus oryzae and wastewater generated from potato processing industry yields better lipid production [28]. Based on the similar assumptions, an attempt has been made in the present investigation to utilize the wastewater generated in each fermentation cycle of the medium was reused for the next respective cycle of the same production medium. The results mentioned in Figure 5 and 6 clearly indicate the fact that in the first cycle of fermentation lipid yield was optimum at 110 and $180 \mathrm{rpm}$ as compared to the remaining two cycles of the fermentation with the reuse of wastewater. While reusing the water from the earlier cycle with a respective medium, the lipid yield was decreased slowly due to poor utilization of essential minerals and nutrients (as used by yeasts of earlier fermentation cycle). Another reason for reduced yield is utilization of wastewater which might cause a decrease in the concentration of available nutrients and minerals while making the volume $100 \mathrm{ml}$ by the addition of either distilled or waste water in the respective production medium. The extracted lipids from the high yielding medium (P4) in the first cycle was qualitatively analyzed using TLC (Data not shown).

\section{Characterization of FAME by GC-MS and FTIR spectrum}

Extracted and qualitatively identified lipids were carry forward for transesterification reaction using a strong acid catalyst $\left(\mathrm{H}_{2} \mathrm{SO}_{4} 0.12 \%\right)$. Lipids with fatty acid ester linkages (also referred to as saponifiable lipids) and free fatty acids can produce fatty acid methyl esters (FAME) after transesterification reaction which can be used as biodiesel. During transesterification in presence of methanol, both lipids and free fatty acids get converted to FAME in presence of a suitable acid catalyst. Extracted total lipids of about $1 \mathrm{ml}$ were diluted 
with methanol in a ratio of $1: 12$ and the reaction mixture was stirred at $60-70{ }^{\circ} \mathrm{C}$ for 90 min. After sufficient cooling, the reaction mixture was washed with warm water until the $\mathrm{pH}$ becomes neutral. FAME's were separated with the addition of equal volume of ethyl acetate in the reaction mixture. The separated FAME in the upper layer were collected by syringe and analyzed through GC-MS. The various peaks appeared in the GC-MS spectrum (Figure.7) revealed hexadecanoic acid methyl esters prominently with a retention time of 22.814 min. Hexadecanoic acid methyl esters are known as palmitic acid $\left(\mathrm{C}_{17} \mathrm{H}_{34} \mathrm{O}_{2}\right)$ methyl esters. Other peaks appeared in the spectrum indicate the saturated and unsaturated fatty acid methyl esters which might play a crucial role in biodiesel properties.

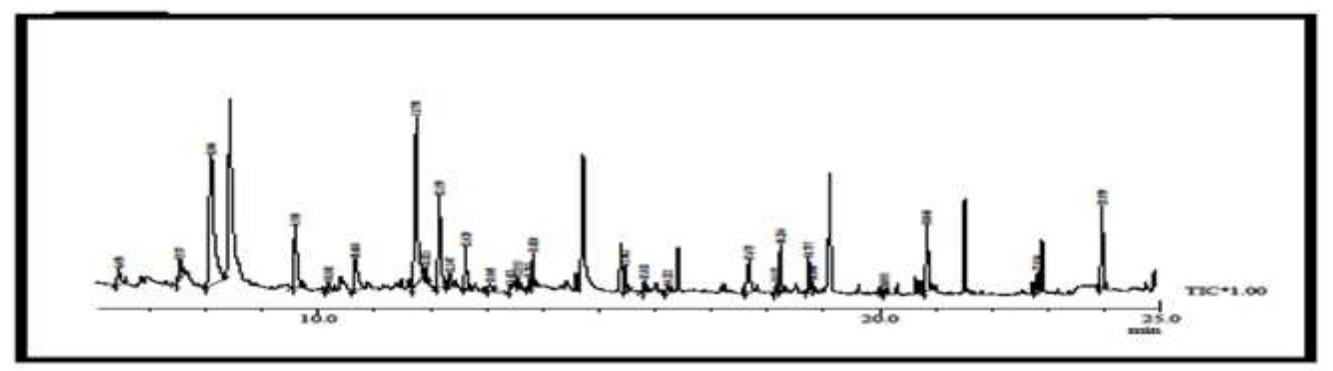

Figure 7. GC chromatogram of biodiesel (FAME) from oil extracted from C.tropicalis with waste water recycling medium and pineapple waste as carbon source.

FTIR spectrum (Figure 8) of produced FAME indicates the characteristic peak $\mathrm{C}=\mathrm{O}$ stretching band of methyl esters at $1740 \mathrm{~cm}^{-1}$ and $\mathrm{C}-\mathrm{O}$ stretching bands at 1171, 1197 and $1245 \mathrm{~cm}^{-1}$.

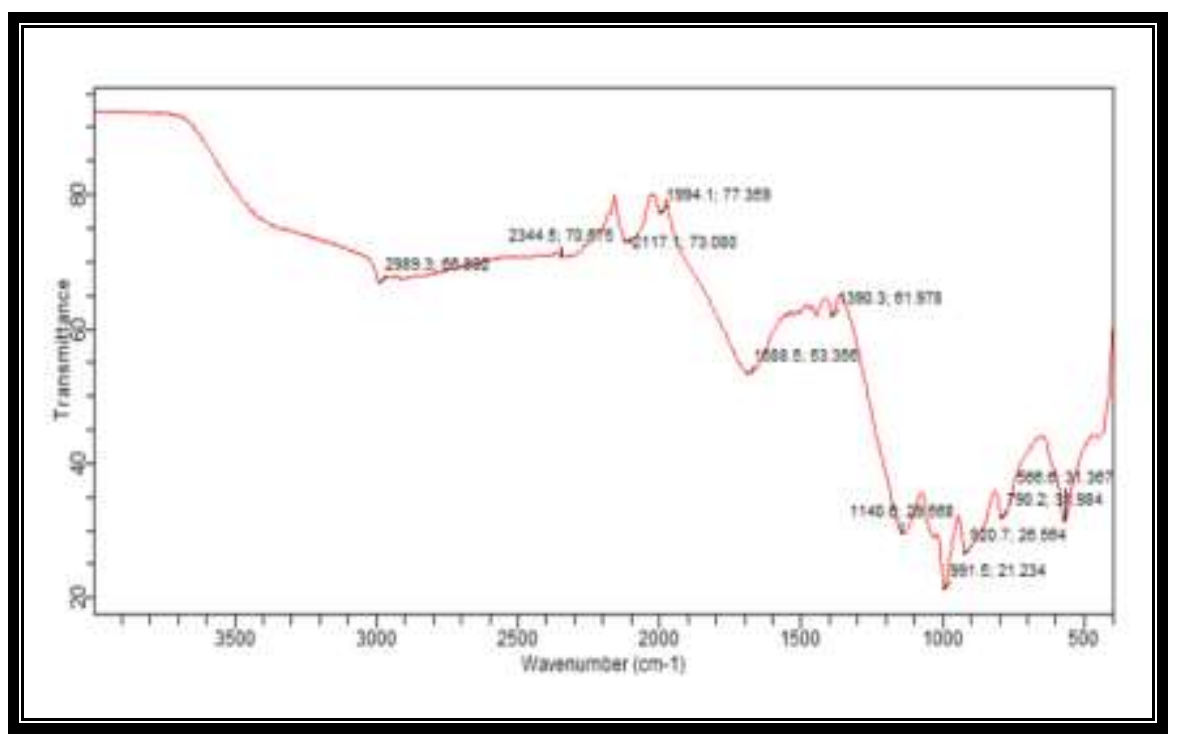

Figure 8. FTIR spectrum of biodiesel from C.tropicalis using waste water and pineapple waste as a carbon source

The region from $1800-1700 \mathrm{~cm}^{-1}$, can be attributed to the stretching of $\mathrm{C}=\mathrm{O}$, which is typical of esters and thus are common in both FAME and refined oil spectra [29]. The peak at $1377 \mathrm{~cm}^{-1}$ can be assigned to the glycerol group which is absent in the obtained FTIR spectrum and confirms the formed FAME is free from glycerol and therefore it confirmed the fact that obtained biodiesel is in pure form [30]. Another confirmation of FAME is with stretching absorbance at $1196 \mathrm{~cm}^{-1}$, is typical of $\mathrm{CH}_{3}$ group of biodiesel [31]. 


\section{CONCLUSION}

In present investigation an attempt has been made to use pineapple waste peels as a possible carbon source for fermentation medium in combination with the municipal wastewater for biodiesel production using Candida tropicalis (MF510172). It is concluded that pineapple waste peels and filtered municipal wastewater used in the study, proved to be to be an ideal, cost effective and eco-friendly step contributing to minimise the problem associated with the waste management and to a certain extent as a source of bioenergy. The lipids extracted from Candida tropicalis (MF510172) were transesterified using acid catalyst and resulting FAME's were palmitic acid methyl esters as confirmed by GC-MS and FTIR spectrum.

Funding: "This research received no external funding"

Conflicts of Interest: Authors have no conflict of interest.

\section{REFERENCES}

1. Luque R, Lovett JC, Datta B, Clancy J, Campelo JM, Romero AA. Biodiesel as feasible petrol fuel replacement: a multidisciplinary overview. Energy \& Environmental Science. 2010;3(11):1706-21.

2. Sagar NA, Pareek S, Sharma S, Yahia EM. Lobo MG. Fruit and vegetable waste: Bioactive compounds, their extraction, and possible utilization. Comprehensive Reviews in Food Science and Food Safety. 2018 May;17(3):512-31.

3. Siti Roha AM, Zainal S, Noriham A, Nadzirah KZ. Determination of sugar content in pineapple waste variety N36. Int. Food Res. J. 2013;20(4):1941-3.

4. Chen XF, Huang C, Xiong L, Chen Y, Ma LL. Oil production on wastewaters after butanol fermentation by oleaginous yeast Trichosporon coremiiforme. Bioresource technology. 2012 Aug $1 ; 118: 594-7$.

5. Gouda MK, Omar SH, Aouad LM. Single cell oil production by Gordonia sp. DG using agroindustrial wastes. World Journal of Microbiology and Biotechnology. 2008 Sep 1;24(9):1703.

6. Huang $\mathrm{C}$, Zong $\mathrm{MH}, \mathrm{Wu} \mathrm{H}$, Liu QP. Microbial oil production from rice straw hydrolysate by Trichosporon fermentans. Bioresource Technology. 2009 Oct 1;100(19):4535-8.

7. Louhasakul Y, Cheirsilp B, Maneerat S, Prasertsan P. Potential use of flocculating oleaginous yeasts for bioconversion of industrial wastes into biodiesel feedstocks. Renewable energy. 2019 Jun 1; 136:1311-9.

8. Karatay SE, Dönmez G. Improving the lipid accumulation properties of the yeast cells for biodiesel production using molasses. Bioresource technology. 2010 Oct 1;101(20):7988-90.

9. Nayak M, Karemore A, Sen R. Performance evaluation of microalgae for concomitant wastewater bioremediation, $\mathrm{CO} 2$ biofixation and lipid biosynthesis for biodiesel application. Algal Research. 2016 Jun 1; 16:216-23.

10. Zhou W, Li Y, Min M, Hu B, Zhang H, Ma X, Li L, Cheng Y, Chen P, Ruan R. Growing wastewater-born microalga Auxenochlorella protothecoides UMN280 on concentrated municipal wastewater for simultaneous nutrient removal and energy feedstock production. Applied Energy. 2012 Oct 1; 98:433-40.

11. Cea M, Sangaletti-Gerhard N, Acuña P, Fuentes I, Jorquera M, Godoy K, Osses F, Navia R. Screening transesterifiable lipid accumulating bacteria from sewage sludge for biodiesel production. Biotechnology Reports. 2015 Dec 1; 8:116-23.

12. Kwolek-Mirek M, Zadrag-Tecza R. Comparison of methods used for assessing the viability and vitality of yeast cells. FEMS yeast research. 2014 Nov 1;14(7):1068-79.

13. Hartman TL. The use of Sudan Black B as a bacterial fat stain. Stain technology. 1940 Jan 1;15(1):23-8.

14. Liu CH, Young SS, Chang TC, Lee CF. Candida dajiaensis sp. nov., Candida yuanshanicus sp. nov., Candida jianshihensis sp. nov., and Candida sanyiensis sp. nov., four anamorphic, 
ascomycetous yeast species isolated from soil in Taiwan. FEMS yeast research. 2008 Aug 1;8(5):815-22.

15. Chang YH, Chang KS, Lee CF, Hsu CL, Huang CW, Jang HD. Microbial lipid production by oleaginous yeast Cryptococcus sp. in the batch cultures using corncob hydrolysate as carbon source. Biomass and bioenergy. 2015 Jan 1; 72:95-103.

16. Ranjith Kumar R, Hanumantha Rao P, Arumugam M. Lipid extraction methods from microalgae: a comprehensive review. Frontiers in Energy Research. 2015 Jan 8; 2:61.

17. Thorpe RF, Ratledge C. Fatty Acids of Triglycerides and Phospholipids from a Thermotolerant Strain of Candida tropicalis Grown on n-Alkanes at 30 and $40^{\circ}$ C. Microbiology. 1973 Sep 1;78(1):203-6.

18. Zheng S, Kates M, Dubé MA, McLean DD. Acid-catalyzed production of biodiesel from waste frying oil. Biomass and bioenergy. 2006 Mar 1;30(3):267-72.

19. Assemany PP, Calijuri ML, do Couto ED, Santiago AF, Dos Reis AJ. Biodiesel from wastewater: lipid production in high rate algal pond receiving disinfected effluent. Water Science and Technology. 2015 Apr 1;71(8):1229-34.

20. Ratledge $\mathrm{CO}$, Tan $\mathrm{KH}$. Oils and fats: production, degradation and utilization by yeasts. Yeast biotechnology and biocatalysis. 1990:223-54.

21. Ageitos JM, Vallejo JA, Veiga-Crespo P, Villa TG. Oily yeasts as oleaginous cell factories. Applied microbiology and biotechnology. 2011 May 1;90(4):1219-27.

22. Dey $\mathrm{P}$, Maiti MK. Molecular characterization of a novel isolate of $\mathrm{C}$ andida tropicalis for enhanced lipid production. Journal of applied microbiology. 2013 May;114(5):1357-68.

23. Zhou Y, Han LR, He HW, Sang B, Yu DL, Feng JT, Zhang X. Effects of agitation, aeration and temperature on production of a novel glycoprotein GP-1 by Streptomyces kanasenisi ZX01 and scale-up based on volumetric oxygen transfer coefficient. Molecules. 2018;23(1):125.

24. Gupta N, Manikandan NA, Pakshirajan K. Real-time lipid production and dairy wastewater treatment using Rhodococcus opacus in a bioreactor under fed-batch, continuous and continuous cell recycling modes for potential biodiesel application. Biofuels. 2018 Mar 4;9(2):239-45.

25. Mantzouridou F, Roukas T, Kotzekidou P. Effect of the aeration rate and agitation speed on $\beta$ carotene production and morphology of Blakeslea trispora in a stirred tank reactor: mathematical modeling. Biochemical Engineering Journal. 2002 Mar 1;10(2):123-35.

26. Bandaiphet $C$, Prasertsan $P$. Effect of aeration and agitation rates and scale-up on oxygen transfer coefficient, $\mathrm{kLa}$ in exopolysaccharide production from Enterobacter cloacae WD7. Carbohydrate Polymers. 2006 Oct 27;66(2):216-28.

27. Bellou S, Makri A, Sarris D, Michos K, Rentoumi P, Celik A, Papanikolaou S, Aggelis G. The olive mill wastewater as substrate for single cell oil production by Zygomycetes. Journal of Biotechnology. 2014 Jan 20; 170:50-9.

28. Muniraj IK, Xiao L, Hu Z, Zhan X, Shi J. Microbial lipid production from potato processing wastewater using oleaginous filamentous fungi Aspergillus oryzae. water research. 2013 Jun 15;47(10):3477-83.

29. Soares IP, Rezende TF, Silva RC, Castro EV, Fortes IC. Multivariate calibration by variable selection for blends of raw soybean oil/biodiesel from different sources using Fourier transform infrared spectroscopy (FTIR) spectra data. Energy \& Fuels. 2008 Feb 29;22(3):2079-83.

30. Dubé MA, Zheng S, McLean DD, Kates M. A comparison of attenuated total reflectance-FTIR spectroscopy and GPC for monitoring biodiesel production. Journal of the American Oil Chemists' Society. 2004 Jun;81(6):599-603.

31. Rabelo SN, Ferraz VP, Oliveira LS, Franca AS. FTIR analysis for quantification of fatty acid methyl esters in biodiesel produced by microwave-assisted transesterification. International Journal of Environmental Science and Development. 2015 Dec 1;6(12):964.

(C) 5 (1) 2018 by the authors. Submitted for possible open access publication
under the terms and conditions of the Creative Commons Attribution
(CC BY NC) license (https://creativecommons.org/licenses/by-nc/4.0/). 